\title{
Analysis on the Effects of Cut-Outs in Hollow Inconel 718 Gas Turbine Shafts
}

\author{
Kaushik V. Prasad, Karthik Nagendra, Hiriyannaiah Adarsha, Abhijeeth Nagaraj, \\ Venkatachar Ravinarayan, Venkatesh Sandeep, Madihalli Kenchappa Ranganatha Swamy \\ Department of Mechanical engineering, SET-Jain University, Ramanagara, India \\ Email:enn.karthik@gmail.com
}

How to cite this paper: Prasad, K.V., Nagendra, K., Adarsha, H., Nagaraj, A., Ravinarayan, V., Sandeep, V. and Ranganatha Swamy, M.K. (2018) Analysis on the Effects of Cut-Outs in Hollow Inconel 718 Gas Turbine Shafts. Open Journal of Applied Sciences, 8, 304-313.

https://doi.org/10.4236/ojapps.2018.87023

Received: June 6, 2018

Accepted: July 27, 2018

Published: July 30, 2018

Copyright $\odot 2018$ by authors and Scientific Research Publishing Inc. This work is licensed under the Creative Commons Attribution International License (CC BY 4.0).

http://creativecommons.org/licenses/by/4.0/

\begin{abstract}
Gasturbines are provided with cut-outs for minimizing vibrations. Round cut-outs are usually favored but there are various designs which offer more advantages over the circular shape. The objective of this work was to compare stress reduction during the induced vibration in the hollow gas turbine shafts by introducing different cut-outs. Round, square and elliptical cut-outs under different orientations were compared. It is observed that a square cutout at $45^{\circ}$ orientation has the least stress concentration. This is due to the effective orientation of plastic strains along the principal axis.
\end{abstract}

\section{Keywords}

Static Analysis, Crack Propagation, Non Linear Analysis, Stress

Concentration, Square Cutouts

\section{Introduction}

A gas turbine, known as a combustion turbine is an inward burning motor. It consists of an upstream rotary compressor coupled to a downstream turbine and an ignition chamber at the center. Gasturbines hafts accumulate oil from the vicinity and result in vibrations; hence they are provided with cutouts for minimizing vibrations by draining the oil. Cutouts are generally circular, square or elliptical in shape. The shape of the cutouts is dependent on their application. For example, sewer vents are either circular or roundabout. Similarly plane windows are rectangular in shape with chamfer at the corners [1]. In plane structures, definite shapes are found as access ports for electrical and mechanical systems or for the reduction of weight [2]. Practically round cutouts are favored due to its simple geometry but there are various designs which offer more advantages over the circular shape. The stress distribution around the cutouts and 
along the shaft gives a clear idea of the geometry and orientation of cutouts for reduction of vibration in gas turbines [3].

Ghannadpour et al. [4] have demonstrated in their study that buckling strength of rectangular laminated composites reduces with increase in hole diameter. Also for elliptical cut-outs it is observed that buckling strength increases when loaded in the direction along their major axis. Sivakumara et al. [5] optimized the operating frequencies of the laminated composites by introducing cut-outs. Optimization was carried using Genetic Algorithm (GA) technique. It was reported that circular cut-out minimizes the weight for 1st and 2nd natural frequencies compared to elliptical cut-outs. Levraea et al. [6] investigated the variation in the frequencies of the panels with and without eccentrical cut-outs and observed that the variation was less than $10 \%$ and increased with the cut-out size.

Rezaeepazh et al. [7] have developed analytical and numerical model to determine normal stress in composite plates of different cut-out shapes. Ahmed Noor et al. [8] have developed numerical model using first order shear theory to evaluate the thermal buckling of laminated composite with different cut-outs.

From the review of above [1]-[8], it is seen that most of the authors have worked on plates and composites subjected to cut-outs and have carried out the stress analysis. But very scarce amount of work reports on the analysis in a hollow shaft with the introduction of cut-outs. In the present work a comparative study is made for different cut-outs (round, square and elliptical) in hollow Inconel gas turbine shaft and the stress distribution is studied under induced vibrations conditions.

\section{Methodology}

A hollow shaft was created with the following dimensions. Outer diameter of shaft was taken as $75 \mathrm{~mm}$, inner diameter as $65 \mathrm{~mm}$ and length as $300 \mathrm{~mm}$. The diameter of circular cut-out was taken as $6 \mathrm{~mm}$, elliptical cut-out dimension as 12 $\times 6 \mathrm{~mm}$ and square cut-out dimensions as $6 \times 6 \mathrm{~mm}$. The model was created using Catia V19 and cut-outs of square, elliptical and circular configuration were introduced perpendicular and inclined $\left(45^{\circ}\right)$ to the shaft axis. This was meshed with HEX (SOLID185) using ANSYS 14 and was subjected to torque. Analysis of the shaft with cut-out was carried out by subjecting it to its plastic limit. The maximum shear stress at cut-outs was tabulated and stress concentration is calculated by using the below formula.

Stress Concentration $=$ Maximum Stress at cut out $/$ Nominal Stress

$$
K \alpha=\frac{\sigma \max }{\sigma \text { nom }}
$$

The above equation is taken from ref. [9]. Using the torque equation nominal stress is calculated. ANSYS macros were written for different slots for stress calculation. Vonmises Stress, Principal Stress, Equivalent strain and plastic strain for the cut-out regions were calculated and tabulated. The results were compared 
between cut-outs of different geometries.

\subsection{Material Properties}

Nickel based superalloys are used extensively in gas turbines and combustor areas of the motor. They have high creep and fatigue resistance, can withstand high temperatures for long periods of time and reduces processing and element energy costs. Inconel is an austenitic nickel-chromium based superalloy. They are resistant to oxidation and corrosion and are used in extreme environments. Up to temperatures of $650^{\circ} \mathrm{C}$, Inconel 718 is usually used. The material properties of Inconel 718 are given in Table 1 and Table 2.

The properties of the metals can be found in ref. [10] [11] and references therein.

\subsection{Element Type Description}

SOLID185 is for modelling of 3D solid structures. It is characterized by eight hubs that has three degrees of flexibility at every hub; interpretations in hubs along $\mathrm{x}, \mathrm{y}$ and $\mathrm{z}$ axes. The element has plasticity, stress stiffening, large deflection, and large strain capabilities. The element is defined by eight nodes and orthotropic material properties.

\subsection{Numerical Models}

The numerical models developed for various cut-out geometries are as shown in Figures 1-5.

Table 1. Composition of Inconel 718.

\begin{tabular}{cc}
\hline Element & Content \\
\hline $\mathrm{Ni}+\mathrm{Co}$ & $50 \%-55 \%$ \\
$\mathrm{Cr}$ & $17 \%-21 \%$ \\
$\mathrm{Nb}+\mathrm{Ta}$ & $4.75 \%-5.5 \%$ \\
$\mathrm{Mo}$ & $2.8 \%-3.3 \%$ \\
$\mathrm{Ti}$ & $0.65 \%-1.15 \%$ \\
$\mathrm{Al}$ & $0.2 \%-0.8 \%$ \\
$\mathrm{Fe}$ & Balance
\end{tabular}

Table 2. Mechanical properties of Inconel 718 alloy.

\begin{tabular}{cc}
\hline Property & Metric \\
\hline Density & $8.19 \mathrm{~g} / \mathrm{cm}^{3}$ \\
Melting point & $13366^{\circ} \mathrm{C}$ \\
Co-efficient of expansion & $13.0 \mu \mathrm{m} / \mathrm{m} \cdot{ }^{\circ} \mathrm{C}\left(20^{\circ} \mathrm{C}-100^{\circ} \mathrm{C}\right)$ \\
Modulus of rigidity & $77.2 \mathrm{kN} / \mathrm{mm}^{2}$ \\
Modulus of elasticity & $204.9 \mathrm{kN} / \mathrm{mm}^{2}$ \\
\hline
\end{tabular}




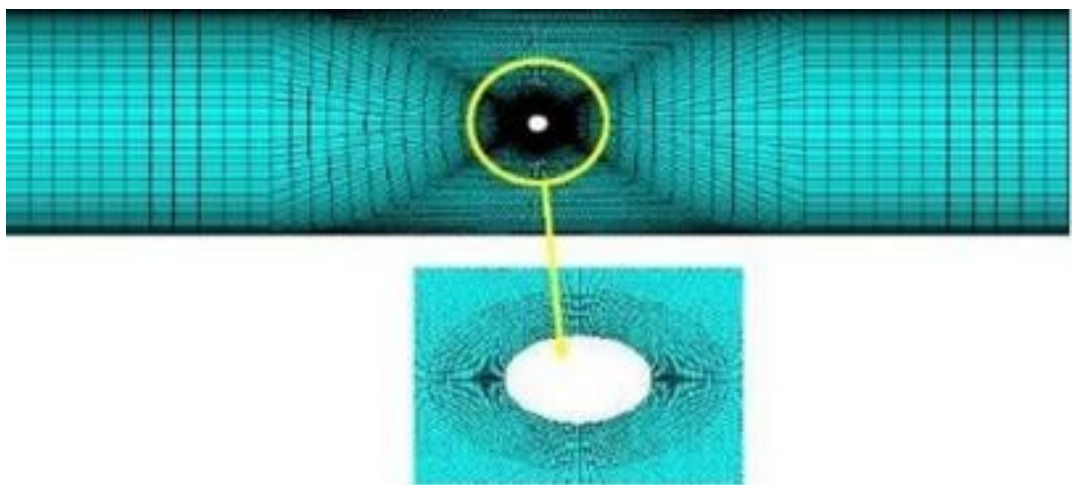

Figure 1. Hollow shaft with circular cut-out showing region of interest with fine mesh being magnified. Element type used: SOLID 185 Mesh type: Hex mesh, Number of nodes: 64174 Number of elements: 58860 .
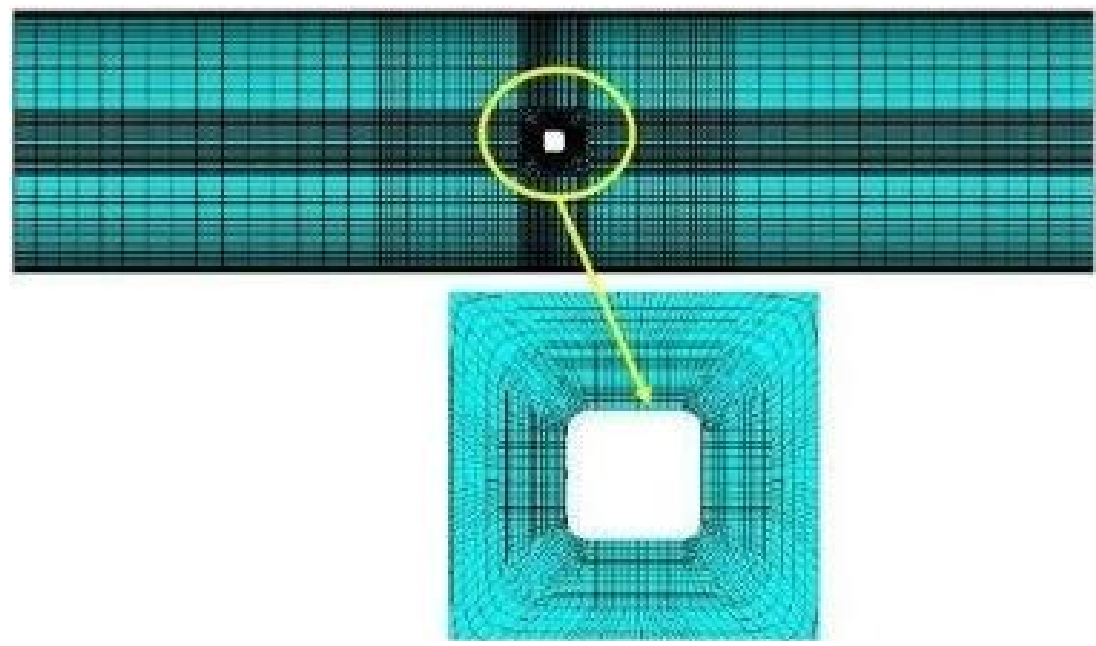

Figure 2. Hollow shaft with square cut-out $\left(0^{\circ}\right)$ showing region of interest with fine mesh being magnified. Element type used: SOLID 185 Mesh type: Hex mesh, Number of nodes: 197474 Number of elements: 174576.
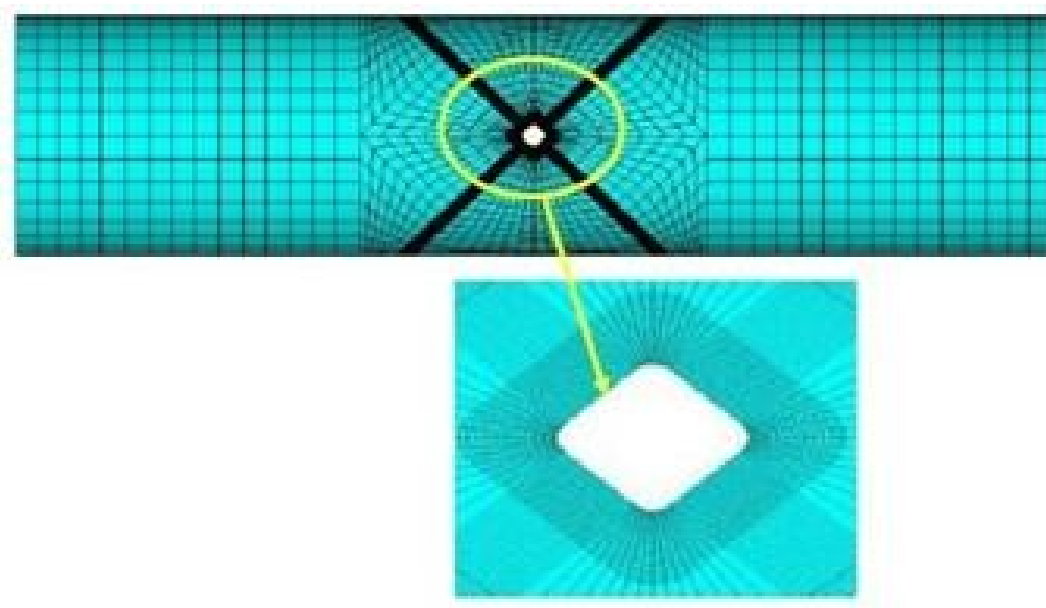

Figure 3. Hollow shaft with square cut-out $\left(45^{\circ}\right)$ showing region of interest with fine mesh being magnified. Element type used: SOLID 185 Mesh type: Hex mesh, Number of nodes: 150144 Number of elements: 135124. 

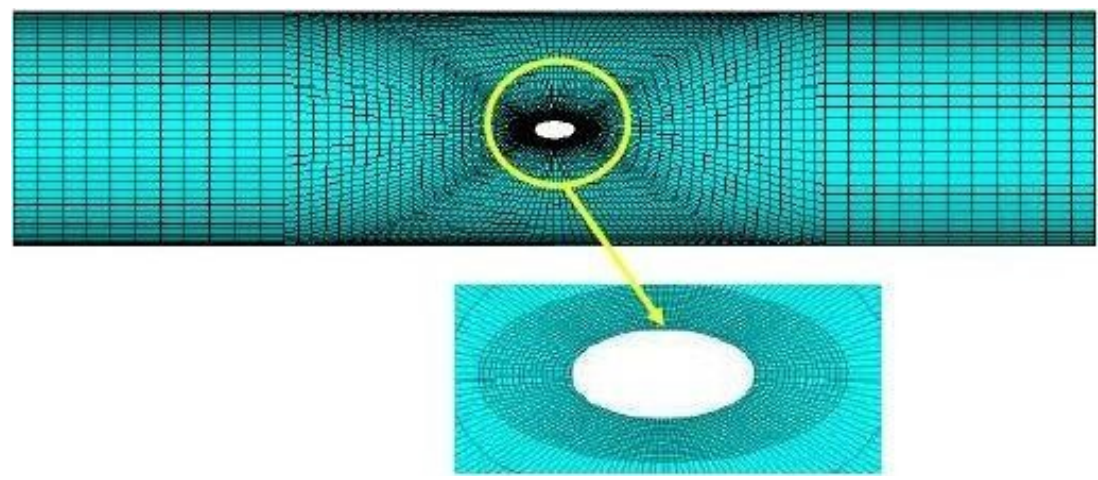

Figure 4. Hollow shaft with elliptical cut-out $\left(0^{\circ}\right)$ showing region of interest with fine mesh being magnified, Element type used: SOLID 185 Mesh type: Hex mesh, Number of nodes: 111880 Number of elements: 102960.
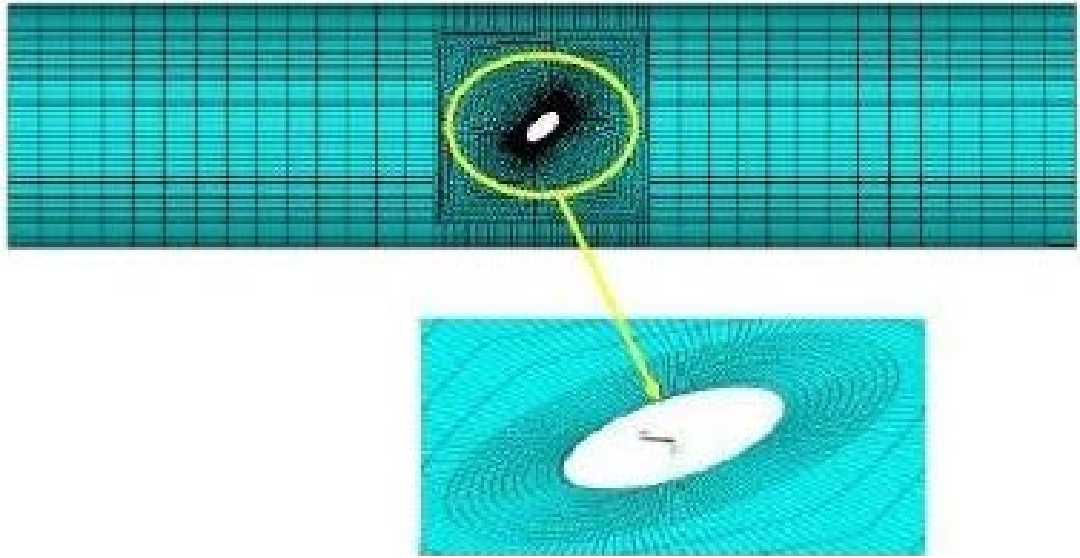

Figure 5. Hollow shaft with elliptical cut-out of $\left(45^{\circ}\right)$ showing region of interest with fine mesh being magnified. Element type used: SOLID 185 Mesh type: Hex mesh, Number of nodes: 113377 Number of elements: 99560.

\subsection{Boundary Conditions}

The hollow shaft was subjected to the boundary conditions as shown in the Figure 6. Rigid connections are provided at both the sides. Torque was applied on one end and the other end was fixed. Power of $12.5 \mathrm{MW}$ and torque of 23.87324 $\mathrm{X} 106 \mathrm{~N}-\mathrm{mm}$ is applied. The power and torque has been assumed suitably.

\section{Results and Discussions}

The behavior of different cutouts and its orientations upon application of torsional moment were studied. Crack initiation starts at geometric discontinuity and crack propagates when component is under plastic deformation. Cracks are initiated and propagated due to tensile stress, whereas any cracks or voids in the material are closed by compressive stress.

Von Mises stress is a combination of tensile and compressive stress. Compressive stress region and tensile stress region cannot be distinguished by it. Hence for better understanding principal stress plots are used.

From the Figure 7, when twisting moment is applied on a circular cutout, 


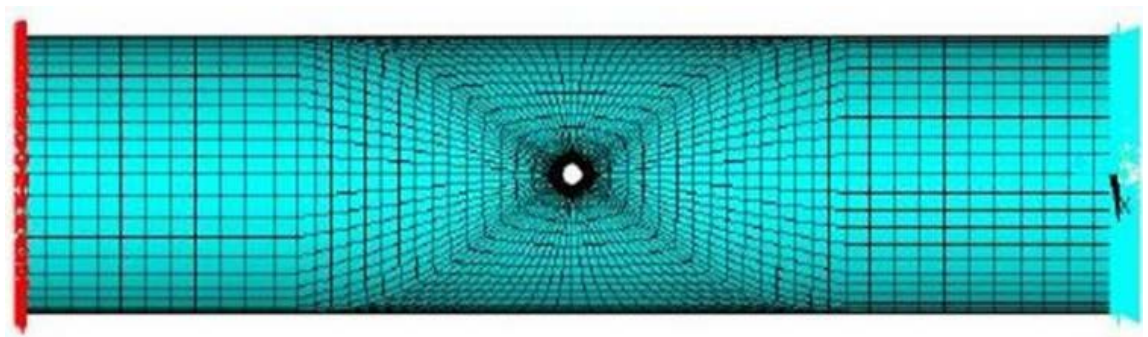

Figure 6. Hollow shaft fixed at one end subject to torsion at the other end.

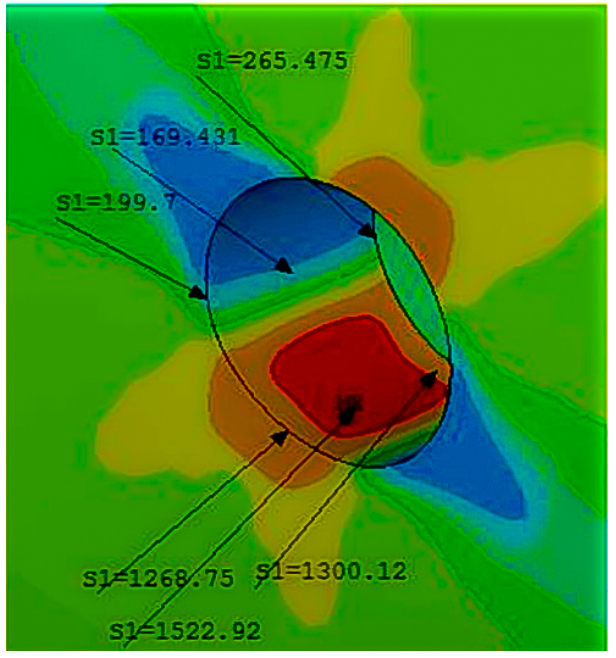

(a)

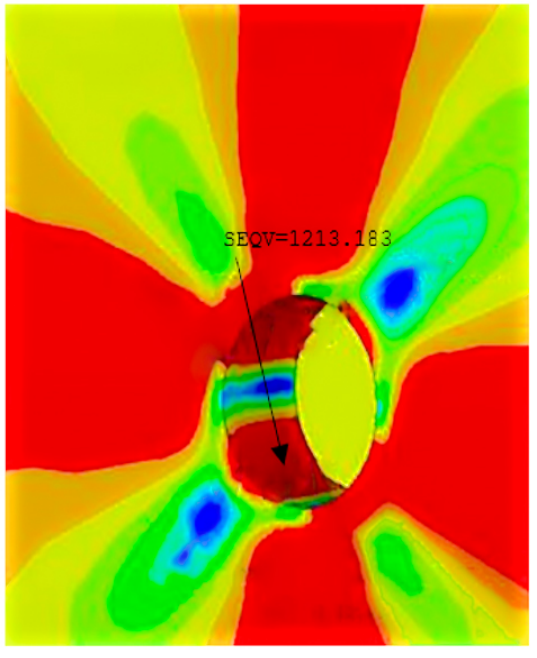

(b)

Figure 7. (a) Principal stress and (b) Von Mises stress plots around a circular cutout.

it deforms in an elliptical manner causing contraction and stretching of the circular hole. The red color region in the cutout plots indicate maximum stress, whereas blue colored region indicates compressive stress which can be seen by plotting minimum principal stress and Von Mises stress.

The maximum principal stress and Von Mises stress around the cutout region are observed to be $1523 \mathrm{MPa}$ and $1212 \mathrm{MPa}$ respectively. The principal strain and equivalent strain at the circular cut-out region. The maximum principal strain and equivalent strain around the cutout region are found to be $1.31 \%$ and $1.91 \%$ respectively.

Figure 8 represents the Principal stress and Von Mises stress plots at the square cut-out $\left(0^{\circ}\right)$ orientation region. The maximum principal stress and Von Mises stress around the cutout region are observed to be $1510 \mathrm{MPa}$ and 1210 MPa respectively. The maximum principal strain and equivalent strain around the cutout region are found to be $1.8 \%$ and $2.91 \%$ respectively.

Figure 9 shows the principal stress and Von Mises stress plots at the square cut-out $\left(45^{\circ}\right)$ orientation region. The maximum principal stress and Von Mises stress around the cutout region are observed to be $1535 \mathrm{MPa}$ and $1211 \mathrm{MPa}$ respectively. The maximum principal strain and equivalent strain around the cutout region are found to be $0.89 \%$ and $0.93 \%$ respectively. 


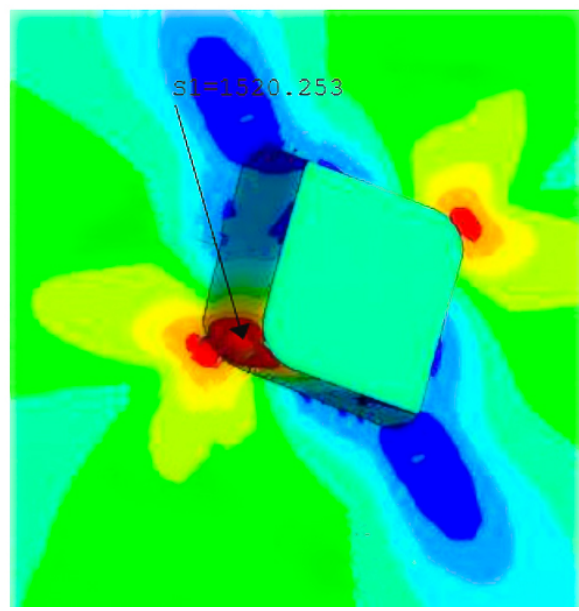

(a)

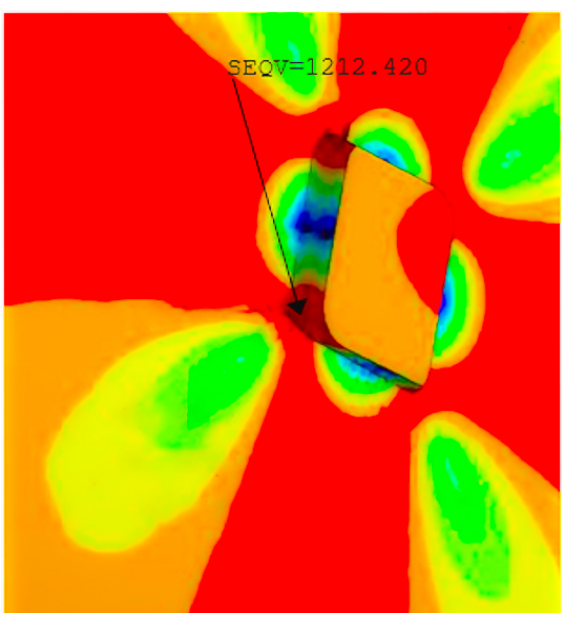

(b)

Figure 8. (a) Principal stress and (b) Von Mises stress around square $\left(0^{\circ}\right)$ cut-out.

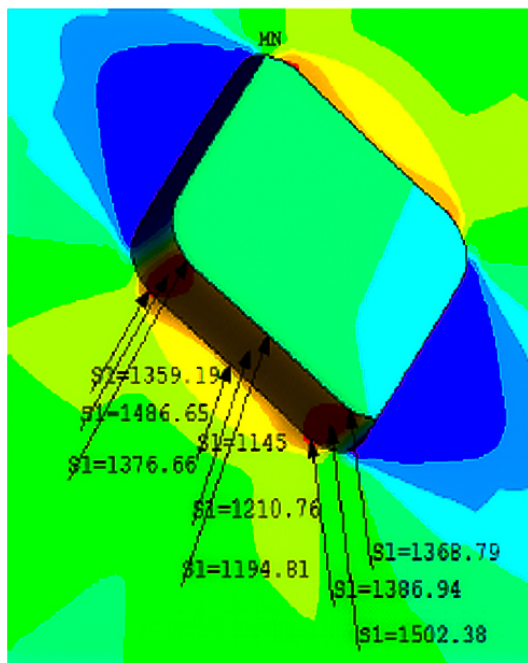

(a)

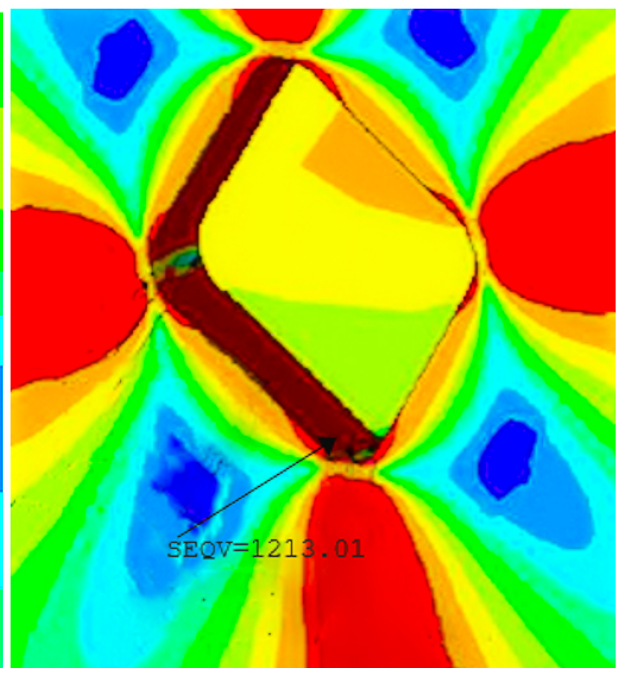

(b)

Figure 9. (a) Principal stress and (b) Von Mises stress around square (45 $)$ cut-out.

Figure 10 shows the principal stress and Von Mises stress plots at the elliptical $\left(0^{\circ}\right)$ orientation cut-out region. The maximum principal stress and Von Mises stress around the cutout region are observed to be $1534 \mathrm{MPa}$ and $1213 \mathrm{MPa}$ respectively. The principal strain and equivalent strain at the elliptical cutout region. The maximum principal strain and equivalent strain around the cutout regions are found to be $1.78 \%$ and $1.8 \%$ respectively.

Figure 11 shows the principal stress and Von Mises stress plots at the elliptical cut-out $\left(45^{\circ}\right)$ region. The maximum principal stress and Von Mises stress around the cutout region are observed to be $1572 \mathrm{MPa}$ and $1213 \mathrm{MPa}$ respectively. The maximum principal strain and equivalent strain around the cutout region are found to be $3.14 \%$ and $3.23 \%$ respectively.

Table 3 shows the results of the analysis carried out in a hollow shaft with the introduction of cut-outs of different geometry and orientation subjected to 


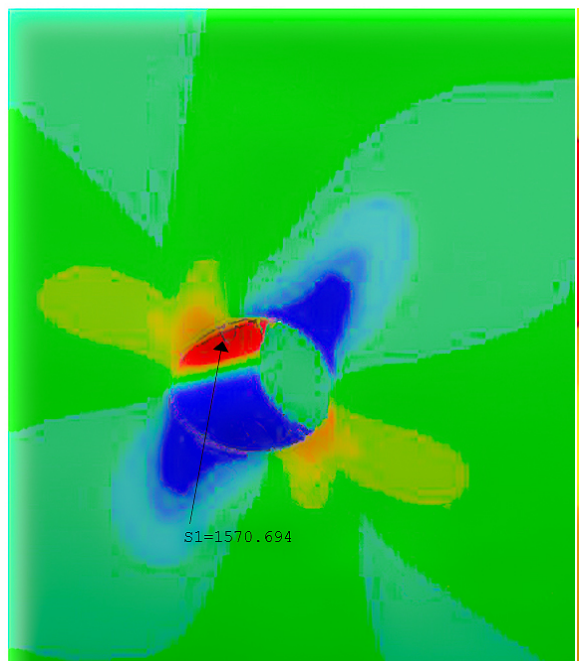

(a)

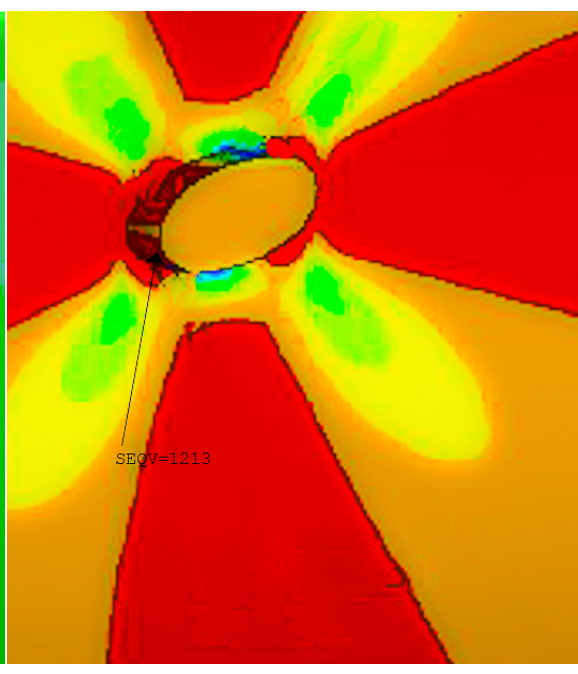

(b)

Figure 10. (a) Principal stress and (b) Von Mises stress plots around elliptical $\left(0^{\circ}\right)$ cutout.

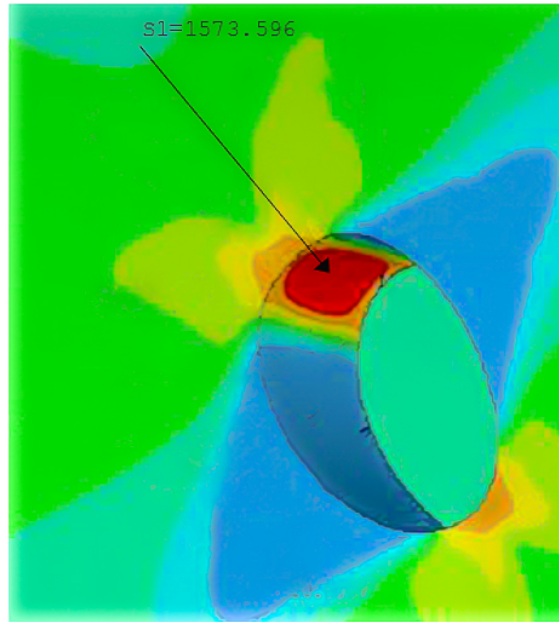

(a)

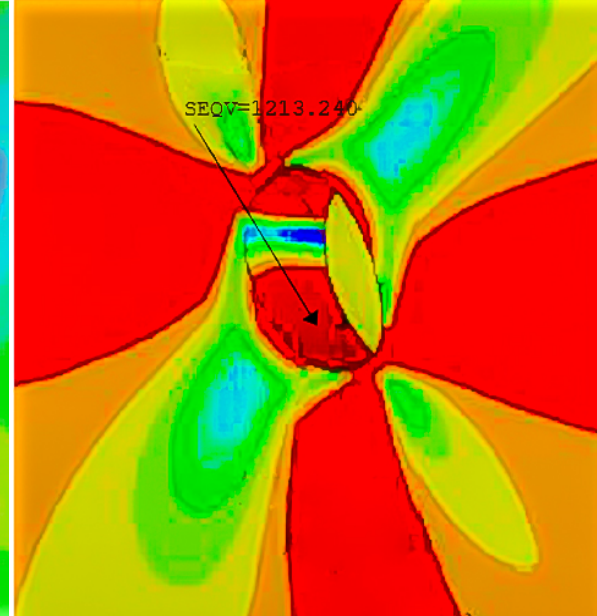

(b)

Figure 11. (a) Principal stress and (b) Von Mises stress plots around elliptical $\left(45^{\circ}\right) \mathrm{cu}-$ tout.

specified boundary condition.

The plastic strain in square cut-out $\left(45^{\circ}\right)$ is observed to be the lowest when compared with cut-outs of other geometry and orientation. It is also observed from Table 1 that values obtained for Von-Mises stress is the same. This is due to the fact that non-linear analysis on the material has been carried out. The stress and strain values varies proportionally up to elastic limit. Once the plastic limit is attained the stress remains constant and only the strain varies which is the characteristic feature of the non-linear analysis.

Also the square cut-out with $45^{\circ}$ orientation contains sides parallel and perpendicular to principal stress directions which in turn minimizes the stress concentration and reduces the plastic strain. The principal stress for square cut-out $\left(45^{\circ}\right)$ orientation is around $1502 \mathrm{MPa}$ while it is maximum for elliptical 
Table 3. Shows the stress and strain values for different cut-outs.

\begin{tabular}{ccccc}
\hline Analytical Model & $\begin{array}{c}\mathbf{1}^{\text {st }} \text { Principal } \\
\text { Stress MPa }\end{array}$ & $\begin{array}{c}\text { Von Mises } \\
\text { Stress MPa }\end{array}$ & $\begin{array}{c}\mathbf{1}^{\text {st }} \text { Principal } \\
\text { Plastic Strain }\end{array}$ & Equivalent Strain \\
\hline Circular & 1527.512 & 1213.183 & 0.01974 & 0.02012 \\
Square $\left(0^{\circ}\right)$ & 1520.253 & 1212.420 & 0.03293 & 0.03410 \\
Square $\left(45^{\circ}\right)$ & 1502.410 & 1213.031 & 0.01536 & 0.01774 \\
Elliptical $\left(0^{\circ}\right)$ & 1570.694 & 1213.093 & 0.01873 & 0.01907 \\
Elliptical $\left(45^{\circ}\right)$ & 1573.596 & 1213.240 & 0.03286 & 0.03358 \\
\hline
\end{tabular}

cut-out $\left(45^{\circ}\right)$. Thus, it is seen that a square cut-out $\left(45^{\circ}\right)$ orientation can be implemented in the design in order to enhance the service life of the components.

\section{Conclusions}

In present study the effect of cut-outs with different geometry and orientation was studied using ANSYS 14 software. Five different cut-out geometries and orientations were introduced on hollow Inconel 718 shaft-circular $\left(0^{\circ}\right)$, square $\left(0^{\circ}\right)$, square $\left(45^{\circ}\right)$, elliptical $\left(0^{\circ}\right)$ and elliptical $\left(45^{\circ}\right)$. The shaft was subjected to a Power of 12.5 MW and torque of $23.87324 \mathrm{X} 106 \mathrm{~N}$-mm with one end fixed. The models were analyzed for principal stress, Von Mises stress along with plastic strain. The following features were observed in the analyzed models:

- The square cut-out with $45^{\circ}$ orientation shows the least plastic strain of 0.01536 . The least value of plastic strain is due to the fact that square cut-out with $45^{\circ}$ orientation contains sides parallel and perpendicular to principal stress directions which in turn minimizes the stress concentration and reduces the plastic strain.

- The Von-Mises stress remains almost same for all cut-out geometries because non-linear analysis is being carried out. The stress is proportional to strain within elastic limit. In plastic region the stress remains constant and strain varies.

- Square cut-outs with $45^{\circ}$ orientation may be implemented in design to improve the service life of the components.

- Further, experimental investigation of simulated models may be carried out which opens arena for further research.

\section{Competing Interests}

The authors declare that there is no conflict of interests. The work being carried out is purely for academic purpose and there are no financial gains to the authors by any means.

\section{References}

[1] Dharmin, P., Khushbu, P. and Chetan, J. (2012) A Review on Stress Analysis of an Infinite Plate with Cut-Outs. International Journal of Scientific and Research Publications, 2, 1-7.

[2] Guo, S., Morishima, R., Zhang, X. and Mills, A. (2009) Cutout Shape and Rein- 
forcement Design for Composite C-Section Beams under Shear Load. Composite Structures, 88, 179-187. https://doi.org/10.1016/j.compstruct.2008.03.001

[3] Mohan, K.M., Rajesh, S., Yogesh, H. and Yeshaswini, B.R. (2013) Study on the Effect of Stress Concentration on Cutout Orientation of Plates with Various Cutouts and Bluntness. International Journal of Modern Engineering Research, 3, 1295-1303.

[4] Ghannadpour, S.A., Najafi, A. and Mohammadi, B. (2006) On the Buckling Behavior of Cross-Ply Laminated Composite Plates Due to Circular/Elliptical Cutouts. Composite Structures, 75, 3-6. https://doi.org/10.1016/j.compstruct.2006.04.071

[5] Sivakumar, K., Iyengar, N.G. and Deb, K. (1998) Optimum Design of Laminated Composite Plates with Cutouts Using Agenetic Algorithm. Composite Structures, 42, 265-279. https://doi.org/10.1016/S0263-8223(98)00072-5

[6] Levraea, V.J., Palazotto, A.N. and Maddux, G.E. (1993) The Effect of Cutout Positioning on the Dynamic Characteristics of a Curved Composite Panel. Composite Structures, 23, 263-272. https://doi.org/10.1016/0263-8223(93)90227-H

[7] Rezaeepazhand, J. and Jafari, M. (2005) Stress Analysis of Perforated Composite Plates. Composite Structures, 71, 463-468.

https://doi.org/10.1016/j.compstruct.2005.09.017

[8] Noor, A.K., Starnes, J.H. and Peters, J.M. (1993) Thermomechanical Buckling and Postbuckling of Multilayered Composite Panels. Composite Structures, 23, 233-251. https://doi.org/10.1016/0263-8223(93)90225-F

[9] Lingaiah, K. (1989) Machine Design Data Handbook, Vol. II (SI and Customary Metric Units). Suma Publishers, Bangalore.

[10] Gale, W.F. and Totemeier, T.C., Eds. (2003) Smithells Metals Reference Book. Butterworth-Heinemann, Oxford.

[11] Smallman, R.E. and Bishop, R.J. (1999) Modern Physical Metallurgy and Materials Engineering. Butterworth-Heinemann, Oxford. 